\title{
Policy volatility and growth
}

\author{
The Anh Pham ${ }^{1}$
}

Received: 24 June 2016 / Accepted: 21 February 2018 / Published online: 21 March 2018 \# ISEG 2018

Abstract The paper aims to examine how fiscal and monetary volatility might affect the balanced economic growth rate using a standard monetary growth model characterized by nominal wage rigidity and productive public spending. The model shows that any type of shock - monetary or fiscal - can generate either a negative or positive relationship between short-run volatility and long-run growth, critically de- pending on the size of government and the elasticity of output with respect to labor/ capital. In particular, given the labor income share, it shows that excessive government spending may cause the impact of fiscal volatility on long-run growth to turn from positive to negative. In addition, a rise in the volatility of the monetary shock is capable of generating either an increase or decrease in the mean of growth. With the range of the labor share values in reality, the model produces results consistent with the fact that the relationship between volatility and growth is generally found empirically to be more negative in developing than in developed countries. The model can be seen as a further explanation for the ambiguous empirical evidence in the existing literature.

Keywords Growth · Volatility · Nominal wage rigidity · Productive public spending · Labor share

JEL classification $\mathrm{E} 32 \cdot \mathrm{E} 60 \cdot \mathrm{O} 42$

The Anh Pham

pham.theanh@yahoo.com; pham.theanh@neu.edu.vn

1 National Economics University, Hanoi, Vietnam 